or idiot, or a lunatic. One would think that in these latter definitions it was desired to bring out the distinction between idiocy and insanity. The word imbecile or idiot is, by medical men at least, always used to signify those who suffer from mental deficiency resulting from disease or malnutrition of the brain, occurring either before birth or in early childhood; and one who becomes fatuous from the degenerative changes of old age, or disease occurring after the years of childhood are past, is, in medical language, a 'dement' or demented, and classed under the head of lunacy. The example given in the schedule is as follows:- Ellen Douglas, mother, widow, age 71, annuitant, born in Canada, imbecile.' Setting aside the question whether an imbecile can legally hold an annuity, most people would conclude that Mrs. Ellen Douglas must have lost her mental faculties after being married. In that case this unfortunate lady ought to have been returned as a lunatic, not an imbecile. Hundreds of householders will thus be induced to use the word 'imbecile' for their lunatic relations, all the more so that it seems a milder or less disagreeable term. It is true that in the schedules people are expecter to state whether those returned as imbecile or idiotic are so from birth ; but then a large number of idiots and imbeciles have been born apparently healthy, and have become imbecile or idiotic, from diseases of the nervous system after birth. The broad distinction between imbeciles or idiots and lunatics is confounded and lost by this unfortunate example. There is no doubt that our statistics of lunacy will thus be of inferior exactness, and not comparable to those of other countries, where the distinction between idiocy and insanity is properly made in the census.

"I am, \&c.,

"William W. Ireland."

\title{
ON THE ADVANTAGES OF TOUGHENED GLASS FOR ASYLUM
} WINDOWS.

Borough Asylum, Gosforth, Newcastle-on-Tyne.

SIR-With reference to your letter to the clerk of the asylum requesting him to inform you if the toughened window glass has given satisfaction here, I have to inform you that it has gradually been substituted for ordinary window glass here, since the 1st of February, 1877, and that I have every reason to be satisfied with it. The cost is about five times that of ordinary glass, but in the four years which it has been in use, it has more than repaid the first outlay, and only one half of the quantity ordered at that date has been used; in addition to its being in the end more economical, it has the advantage that when a pane is broken, which happens occasionally when a good deal of violence is exhibited, the fractured pieces have blunt edges and thus many injuries are avoided. I am, your obedient servant, R. H. B. WICKHAM, F.R.C.S. Medical Superintendent.

The glass is to be obtained of Messrs. Gardner, 453, Strand, London. The measure of the windows has to be sent, and after a few weeks a supply of panes is sent. At Bethlem we have ordered a supply, and in the course of a very short time we shall be glad to show the result of the trial.

Geo. H. SAVAGE.

\section{INTERNATIONAL MEDICAL CONGRESS.}

As a paper is expected from the Superintendent of Gheel it is to be hoped that those among our countrymen who have paid most attention to the more recent developments of the non restraint system, will not only attend but will also contribute plans of their detached houses, and such other home-like or village modes of grouping and treating the insane. 